\title{
Cork suberin as an additive in offset lithographic printing inks
}

\author{
N. Cordeiro ${ }^{\text {a }}$, A. Blayo ${ }^{\text {b }}$, N.M. Belgacem ${ }^{\text {c }}$, A. Gandini ${ }^{\text {b,* }}$, C. Pascoal Neto ${ }^{\text {, }}$, \\ J.-F. LeNest ${ }^{b}$ \\ a Departamento de Química, Universidade da Madeira, 9000 Funchal, Portugal \\ ${ }^{\mathrm{b}}$ Matériaux Polymères, École Française de Papeterie et des Industries Graphiques (INPG), Domaine Universitaire 461, \\ Rue de la Papeterie BP 65, 38402 St. Martin d'Hères, France \\ ${ }^{\mathrm{c}}$ Departamento da Ciência e Tecnologia do Papel, Universidade da Beira Interior, 6200 Covilhã, Portugal \\ d Departamento de Química, Universidade de Aveiro, 3810 Aveiro, Portugal
}

Received 10 May 1999; received in revised form 6 August 1999; accepted 12 August 1999

\begin{abstract}
Suberin oligomers, isolated from cork (Quercus suber L.), were used as additives in 'Waterless' and vegetable-oil ink formulations, in the range of $2-10 \% \mathrm{w} / \mathrm{w}$. The rheological behaviour of the suberin oligomers as well as of the inks, with and without suberin, were investigated as a function of temperature. It was shown that the addition of suberin induces a decrease of viscosity of both inks. The tack of pristine inks, suberin oligomers and their mixtures were determined at different temperatures: the variation of this parameter as a function of time provided information about the drying kinetics of these formulations. The tack of the 'Waterless' ink was found to increase with the introduction of suberin, whereas that of vegetable-oil based counterparts decreased. All the trends observed were interpreted in terms of the differences in composition between the two types of inks. Preliminary printing tests were carried out with the various suberin-containing inks. (C) 2000 Elsevier Science B.V. All rights reserved.
\end{abstract}

Keywords: Cork; Quercus suber L.; Suberin; Additive; Vegetable oil-based ink; Waterless ink; Rheological properties; Viscosity; Tack

\section{Introduction}

Cork from Quercus suber L. is a renewable resource which has been exploited since ancient times. Its conversion into different commodities

\footnotetext{
* Corresponding author. Tel.: + 33-4-76826900; fax: + 334-76826933.

E-mail address: alessandro.gandini@efpg.inpg.fr (A. Gandini)
}

gives rise to $20-30 \%$ of wastes, in the form of fine particles, which are usually burnt for energy purposes. In order to find alternative ways to make good use of this industrial side product, we have undertaken a comprehensive research program which necessarily involved a preliminary study of cork and its components (Cordeiro et al., 1995; Pascoal Neto et al., 1995, 1996; Gil et al., 1997; Cordeiro et al., 1997a; Cordeiro, 1998a; Cordeiro et al., 1998b,c; Lopes et al., 1998), followed by an 
investigation on the use of suberin macromonomers to prepare original polyurethane-type materials (Cordeiro et al., 1997a,b; Cordeiro, 1998a; Cordeiro et al., 1999).

The originality of cork as a vegetable polymeric composite lies in its high content $(40-50 \%)$ of suberin, a crosslinked macromolecule bearing long aliphatic moieties and aromatic ester functions, which indeed give cork its pronounced hydrophobic character. The other components of cork include about $20 \%$ of lignin, $12-20 \%$ of carbohydrates and about $15 \%$ of extractives (Holloway, 1983; Marques and Pereira, 1987; Pereira, 1988).

The alkaline methanolysis of cork (Cordeiro, 1998a) yielded suberin fragments (called suberin herefrom), which have already been fully characterised (Cordeiro et al., 1998b) as a mixture of the following families of products (with chain lengths ranging from $\mathrm{C}_{16}$ to $\mathrm{C}_{24}$ ): $\omega$-hydroxy-monobasic acids, $\alpha, \omega$-dibasic acids, alkanoic acids and 1alkanols. Our results were more comprehensive than those reported previously (Holloway 1972; Kolattukudy, 1977; Holloway 1983; Pereira, 1988), but on the whole agreed with them, except that we also detected a much higher molecular weight fraction not described in those studies (Cordeiro, 1998a; Cordeiro et al., 1998b).

Our suberin samples were also characterised in terms of their physical properties, using DSC, TGA, optical microscopy, densitometry and rheometry (Cordeiro et al., 1998c) and surface energy measurements (Cordeiro et al., 1997a). The most relevant aspect of this part of our study was the discovery that suberin at room temperature was made up of a micro-crystalline fraction and a viscous liquid. As a consequence, this mixture displayed both a plastic and a thixotropic behaviour.

Whereas the exploitation of suberin as a set of polyol macromonomers has been the subject of an ongoing investigation related to macromolecular systhesis (Cordeiro et al., 1997a,b; Cordeiro, 1998a; Cordeiro et al., 1999), to the best of our knowledge, its possible utilization as a non-reactive additive or filler has never before been envisaged. Cork itself has been introduced in polymeric materials as a filler, but even in that specific context, very little has been published (Godinho et al., 1998).

The French laboratory participating in this communication has acquired a sound expertise in the realm of printing inks, including novel compositions, rheological and surface properties and printing performance (Blayo et al., 1993; Blayo and Gandini, 1996; Lanet and Gandini, 1999). Three topics are relevant to this program, viz: (i) the constant need to adapt the rheological properties of the inks to changing printing technologies; (ii) the progressive replacement of fossil-based components by renewable counterparts and (iii) novel ink formulations associated with the progressive inception of offset printing without a dampening solution, with the ensuing elimination of isopropanol as a source of VOC.

The thorough physical and chemical notions acquired in our study of suberin, as summarized above, spurred the present investigation based on the potential interest of this renewable material as a component of offset lithographic printing inks, which are highly viscous colloidal suspensions of oligomeric liquids and solid pigments (Blayo and Gandini, 1996). We envisaged in fact that the microcrystalline character of our product, coupled with adequate rheological and surface properties, could constitute a viable working hypothesis justifying its inclusion in offset inks and the subsequent assessment of the interest of such an investigation.

\section{Experimental}

The suberin samples used in this work were isolated from high-grade cork (kindly supplied by the Champcork Company, Portugal), which was ground to a 60 mesh powder, subsequently treated with a $0.1 \mathrm{M} \mathrm{NaOH}$ solution in methanol, according to the procedure described in a previous publication (Cordeiro et al., 1998b). Two different commercial offset inks were chosen as substrates, namely (i) a red 'Waterless' ink from the Sun Chemical Company, USA, containing petroleum-based diluents; and (ii) a black vegetable oil-based ink from the Trenal Company, Belgium. The dispersion of variable percentages 
Table 1

Viscosity of suberin at different temperatures

\begin{tabular}{lccc}
\hline Temperature $\left({ }^{\circ} \mathrm{C}\right)$ & Viscosity $(\mathrm{Pa} . \mathrm{s})$ & Temperature $\left({ }^{\circ} \mathrm{C}\right)$ & Viscosity $($ Pa.s $)$ \\
\hline 20 & 13900 & 45 & 220 \\
25 & 8730 & 50 & 11 \\
30 & 5180 & 55 & 0.89 \\
32 & 3520 & 57 & 0.39 \\
35 & 2450 & 60 & 0.22 \\
37 & 2010 & 62 & 0.19 \\
40 & 800 & 65 & 0.18 \\
\hline
\end{tabular}

of suberin into the viscous ink media was accomplished by vigorous stirring for 2 min using a suitable mixer from Dispermat.

The rheological measurements were conducted with a cone-plate CSL ${ }_{2}^{500}$ rheometer from TA Instruments, working in a stress-controlled mode, using a $2-\mathrm{cm}$ diameter, $4^{\circ}$ top-angle cone. A wide range of temperatures was explored, each with an accuracy of $\pm 0.1^{\circ} \mathrm{C}$. The stabilisation time was 1 min and thereafter the stress was varied in a linear fashion with respect to time. Three 1-min stages were systematically applied viz: stress-increase, constant-stress and stress decrease.

Tack values were obtained at different speeds and temperatures with a Tack-o-Scope. Measurements were taken automatically at time intervals of $1 \mathrm{~min}$, after having spread $0.6 \mathrm{~cm}^{3}$ of ink for 20 s. Temperature regulation was insured by water circulation inside the driving roller. It is important to underline that the actual numerical values provided by all the tackmeters have no absolute physical significance, and can therefore only be compared internally. Ink transfer onto a standard paper (coated sheets of $110 \mathrm{~g} / \mathrm{m}^{2}$ ) was carried out at room temperature with an IGT printability tester, working at a pressure of $50 \mathrm{kgf}$. The printing speed was $1 \mathrm{~m} / \mathrm{s}$ and the inking roller was supplied with ink during $20 \mathrm{~s}$.

\section{Results and discussion}

As outlined below, systematic comparisons were made with all the parameters studied between the commercial inks and those containing variable amounts of suberin. Moreover, the rheo- logical properties of suberin itself were also assessed.

\subsection{Suberin properties}

The viscosity of pristine suberin was studied as a function of temperature and the data obtained (Table 1) were treated according to the Eyring activation equation:

$\eta=A \exp \frac{E_{\mathrm{a}}}{R T}$

where $E_{\mathrm{a}}$ is the activation energy for viscous flow.

The corresponding plot shown in Fig. 1 clearly displays two distinct regimes $\mathrm{A}$ and $\mathrm{B}$, separated by a transition zone. At the lower temperatures, viz. below $37^{\circ} \mathrm{C}$, the flow was obviously hampered by the presence of the microcrystalline phase, which induced a high value of the activation energy $\left(E_{\mathrm{a}}=88.3 \mathrm{~kJ} / \mathrm{mol}\right)$, whereas above $60^{\circ} \mathrm{C}$, the entirely liquid suberin gave a much lower energy barrier to flow $\left(E_{\mathrm{a}}=34.2 \mathrm{~kJ} / \mathrm{mol}\right)$. This behaviour is in good agreement with the observed

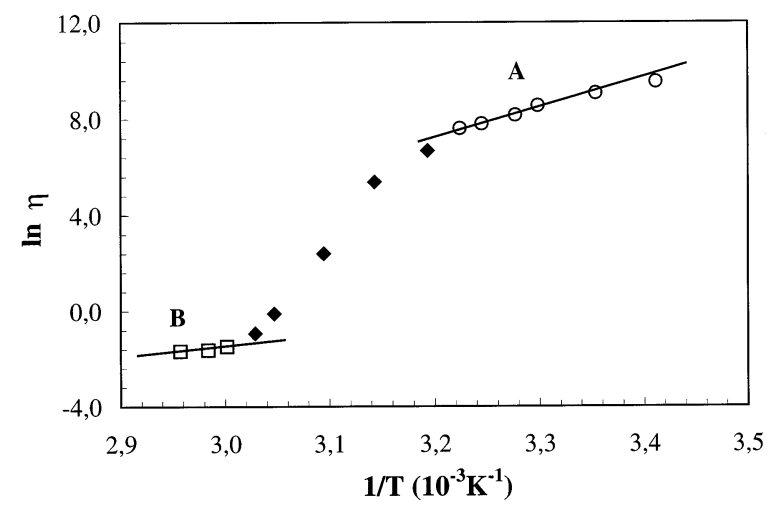

Fig. 1. Eyring plot (Eq. (1)) related to the viscous flow of suberin. 


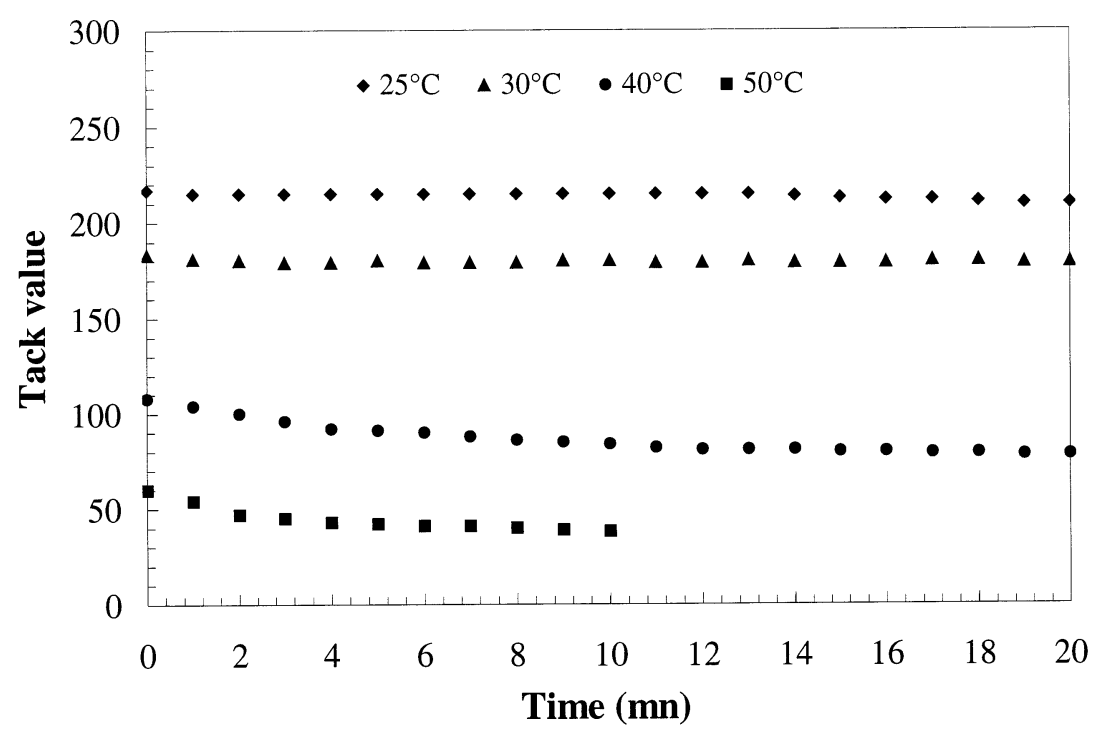

Fig. 2. Evolution of the tack of suberin with time, at different temperatures with a roller speed of $200 \mathrm{~m} / \mathrm{min}$.

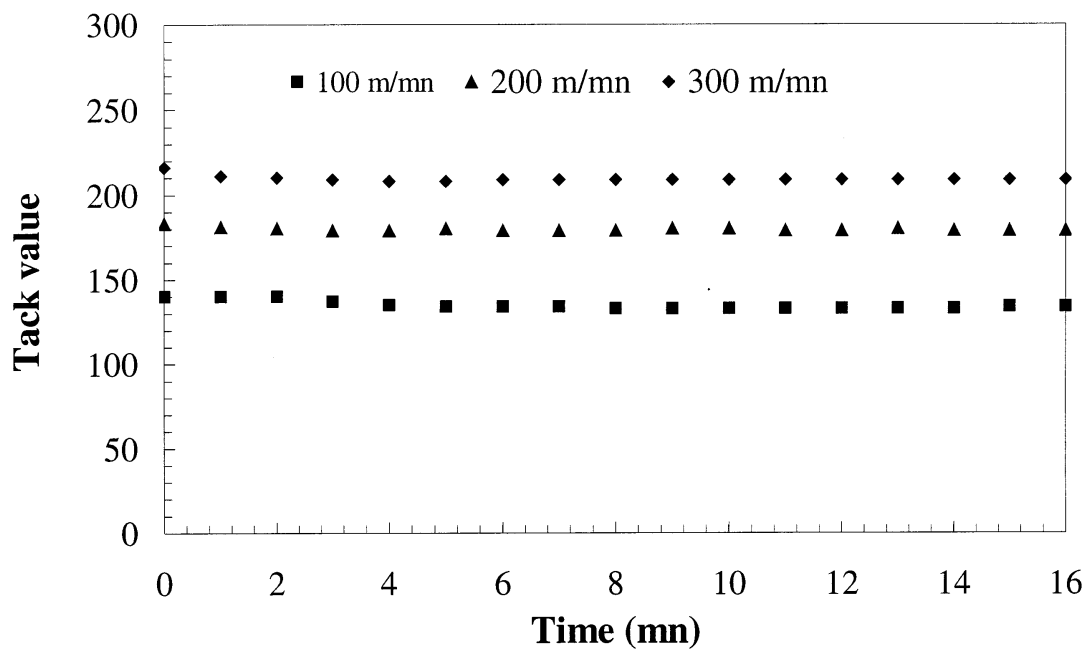

Fig. 3. Evolution of the tack of suberin with time at $30^{\circ} \mathrm{C}$ with different roller speeds.

melting region of semi-crystalline suberin, which was determined previously as occuring between 30 and $50^{\circ} \mathrm{C}$ (Cordeiro et al., 1998c). It is interesting to note that the activation energy of flow in the low temperature region is close to that of the alkyd resins commonly used in offset ink compositions.

The tack is a dynamic rheological parameter defined as the stress required to split a thin film of liquid into two surfaces, and is of great relevance to a number of applications related to the spreading of viscous and adhesive liquids, e.g. painting, coating and printing. In the specific instance of offset lithography, the tack value plays a determining role on the quality of ink transfer.

The tack of suberin was measured as a function of temperature and speed of the instrument rollers, as shown in Figs. 2 and 3. Each value was remarkably stable with time, which indicates that suberin is insensitive to atmospheric oxidation. 
This conclusion is in good agreement with the dominant structures of its components established in a previous study (Cordeiro et al., 1998c), which showed that $\mathrm{C}=\mathrm{C}$ moieties, i.e. the most oxygensensitive groups, represented a negligible contribution. Thus, it can be concluded that if suberin is added to ink formulations, it should not introduce detrimental effects effects on their tack behaviour.

\section{2. 'Waterless' ink}

Fig. 4 shows a typical rheogram of the commercial 'waterless' ink obtained at $30^{\circ} \mathrm{C}$ and indicates the shear-thinning behaviour characteristic of this type of material. In fact, the presence of high polymers ('hard resins') in this formulation gives rise to the well-known deployment of the chains as the shear rate is increased, with the consequent decrease in the resistance to flow. The maximum viscosities of this ink at different temperatures and the corresponding activation energy of flow are given in Table 2 . The relatively high values of viscosity are those required for a good performance in offset printing without a dampening solution.

The evolution of the tack of this ink as a function of time is shown in Fig. 5. The shape of this plot, characterised by the attainment of a maximum value at a characteristic time, is a wellknown feature of printing inks containing drying oils, which undergo drying by oxygen-induced polymerization though their unsaturations (Blayo

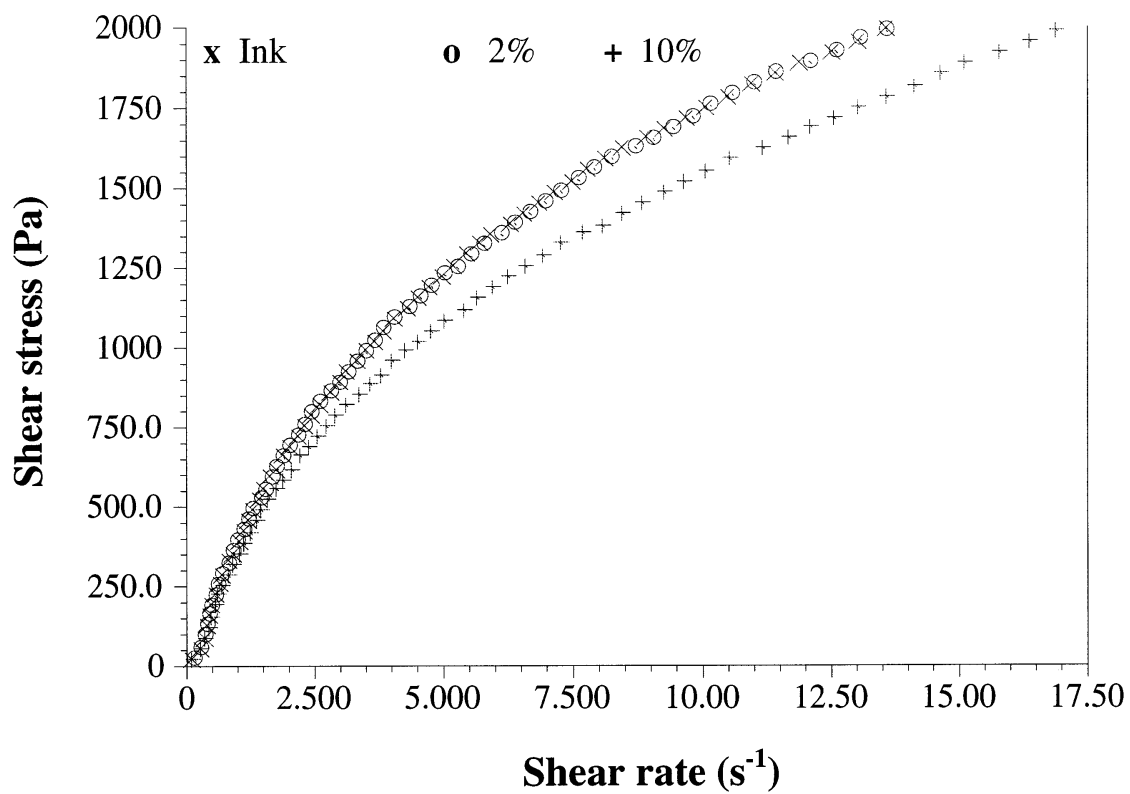

Fig. 4. Rheograms of the 'Waterless' ink at $30^{\circ} \mathrm{C}$, as such and with 2 and $10 \%(\mathrm{w} / \mathrm{w})$ of suberin.

Table 2

Maximum viscosity (measured at low shear rates) and corresponding $E_{\mathrm{a}}$ values of inks as such and with different percentages of added suberin

\begin{tabular}{|c|c|c|c|c|c|}
\hline & \multicolumn{4}{|c|}{ Viscosity (Pa.s) } & $E_{\mathrm{a}}(\mathrm{kJ} / \mathrm{mol})$ \\
\hline Waterless ink & 900 & 451 & 221 & 143 & 49.2 \\
\hline$+10 \%$ Suberin & 845 & 412 & 179 & 95.2 & 58.2 \\
\hline Vegetable-based ink & 51.0 & 17.6 & 6.8 & 3.2 & 73.0 \\
\hline$+2 \%$ Suberin & 42.8 & 15.5 & 6.1 & 2.9 & 71.0 \\
\hline
\end{tabular}




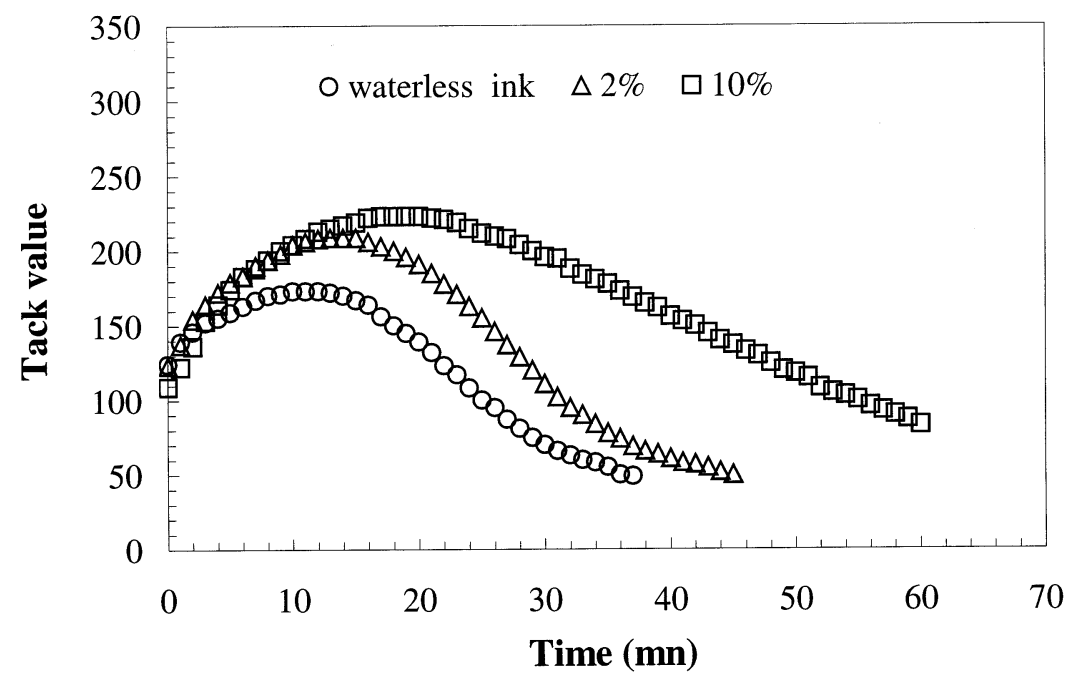

Fig. 5. Evolution of the tack of the 'Waterless' ink as a function of time at $50^{\circ} \mathrm{C}$, as such and with 2 and $10 \%$ w/w of suberin.

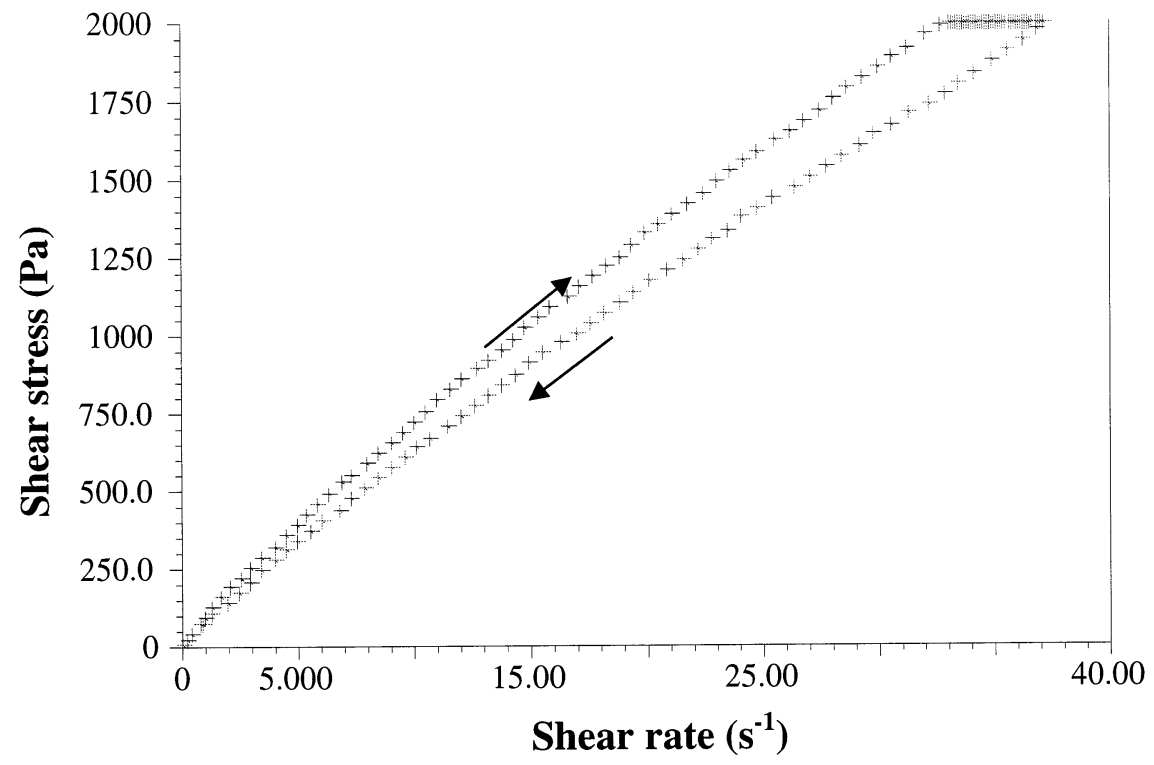

Fig. 6. Rheogram of the vegetable-oil based ink at $30^{\circ} \mathrm{C}$.

et al., 1993). The initial increase is related to both the progressive evaporation of the volatile components of the ink and the increasing molecular weight of the polymerisable structures. The subsequent decrease arises from the actual drying of the film and its corresponding loss of adhesive character. Tack values did not vary strongly with temperature, as expected with this type of ink.

\subsection{Vegetable oil-based ink}

The rheological properties of the vegetable oilbased ink were characterised by a modest shearthinning and a clear-cut thixotropic behaviour, as shown in Fig. 6. Table 2 provides maximum viscosity data at four temperatures and the resulting activation energy of flow, which was higher 
than that of the unmodified 'Waterless' ink. This difference and the accompanying thixotropy of the vegetable oil-based ink suggest the existence of (weak) cohesive interactions between the pigment and the resins in this ink. Fig. 7 gives the features related to the tack of the vegetable oil-based ink, which differed considerably from those related to the 'waterless' ink (Fig. 5) in that no appreciable change was observed as a function of time. This is in tune with (i) the much poorer siccativity of the soya oil contained in the former ink, i.e. with the fact that its drying rate is much lower because of a correspondingly lower proportion of unsaturations; and (ii) its lower content of volatile components.

\subsection{Effects of the addition of suberin}

Suberin was added to both inks at concentrations of either 2 or $10 \% \mathrm{w} / \mathrm{w}$. As shown in Table 2 and Fig. 8, all the resulting mixtures displayed lower viscosities than those of the pristine inks and the decrease was the higher, the higher the suberin content, except at the lower temperatures with the vegetable oil-based ink, where the reverse trend was observed. The following comments are in order to rationalise these results:

- The relative decrease in viscosity associated with the addition of suberin was systematically more pronounced at the higher temperatures because the entire suberine sample was then in the liquid phase.

- The increase in viscosity observed at 20 and $30^{\circ} \mathrm{C}$ for the system vegetable oil-based ink/ suberin, when the latter was raised from 2 to $10 \%$, must be attributed to the poor solubility of suberin in the diluents of that ink resulting in the presence of a growing amount of suspended crystals. The solvent richer 'Waterless' ink induced instead the complete dissolution of the suberin even when it was added in the higher proportion.

Figs. 5 and 7 show the effect of the same suberin additions on the tack of each ink. With the 'waterless' ink (Fig. 5), the presence of different amounts of suberin did not alter the initial tack, but modified progressively the evolution of its value with time in the sense that the higher the suberin content, the higher the maximum tack and the slower its subsequent decrease. This behaviour is readily explained by considering that suberin, although it was soluble in the ink medium, did not introduce any specific interaction with the ink components, but played a retarding role in both the rates of evaporation and drying of the siccative components. It is moreover logical that both retarding effects would be amplified by an increase in the suberin content. In the case of

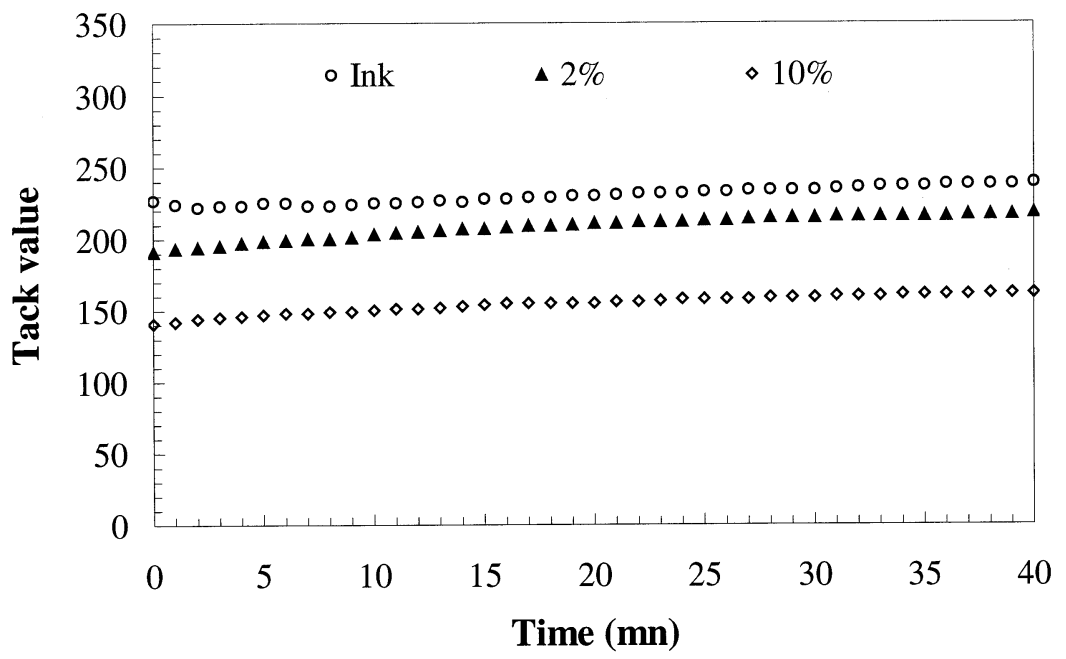

Fig. 7. Evolution of the tack of the vegetable-oil based ink at $25^{\circ} \mathrm{C}$, as such and with 2 and $10 \%$ w/w of suberin. 


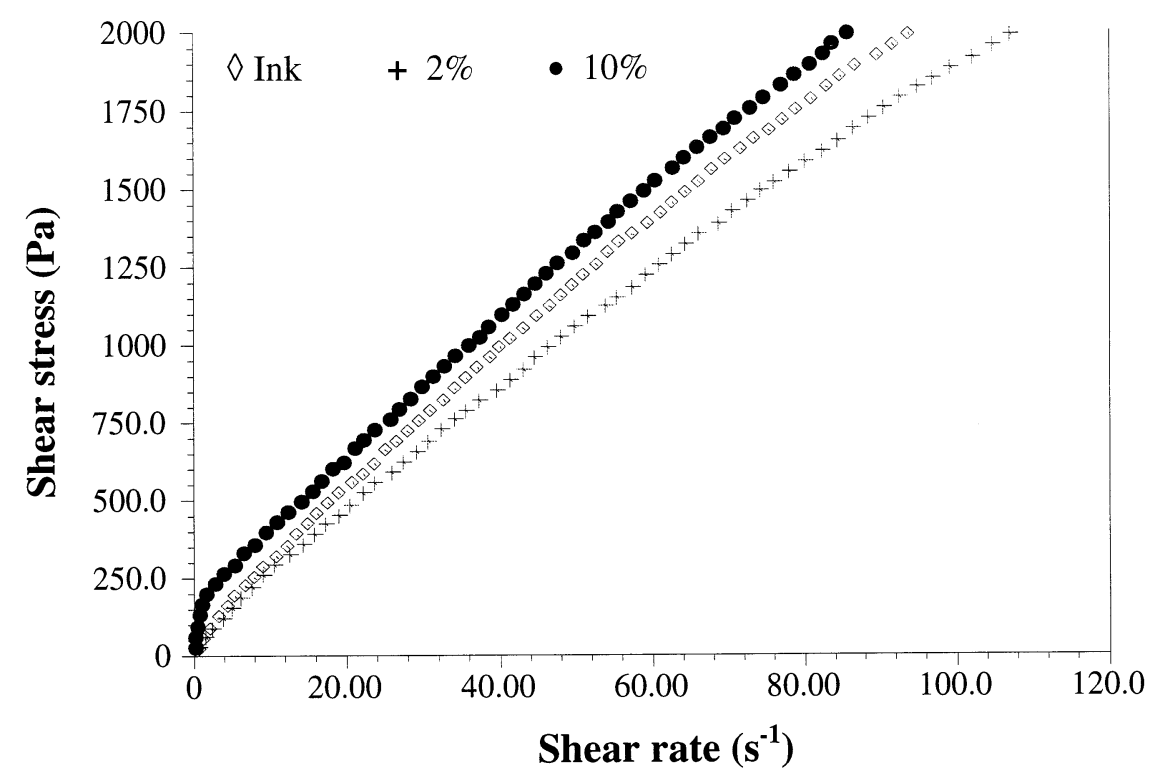

Fig. 8. Rheograms of the vegetable-oil based ink at $30^{\circ} \mathrm{C}$, as such and with 2 and $10 \% \mathrm{w} / \mathrm{w}$ of suberin.

vegetable oil-based ink (Fig. 7), the absence of evolution of the tack with time was maintained, but the actual value decreased with increasing suberin content. At $25^{\circ} \mathrm{C}$, the crystalline portion of suberin, as pointed out above, is likely to be little soluble in the ink medium and thus reduce its cohesive character.

\subsection{Printing tests}

A comparison of the optical properties of papers printed with the pristine and modified inks showed that the reflectance in the visible region was not affected by the presence of suberin in the case of the 'Waterless' ink. Because of the black pigments in the vegetable oil-based ink, reflectance measurements were not meaningful and no conclusions can be drawn at present on the possible effect of suberin on this property. As for gloss, the addition of suberin produced no appreciable change with the 'Waterless' ink studied at 20 and $85^{\circ}$ of incidence. With the vegetable oil-based ink, in both experimental conditions, the addition of suberin induced a progressive decrease of gloss, resulting in a two-fold drop with $10 \%$ of suberin. Although these results must be considered as preliminary, the different behaviour with respect to gloss is again consistent with a much lower solubility of suberin in the vegetable medium resulting in its partial migration to the surface of the ink film after printing.

\section{Conclusion}

The inclusion of suberin-based oligomers, obtained by the methanolysis of cork, in two types of printing inks provided some basic information mostly on their effects on the rheological properties of these highly viscous colloidal suspensions. No detrimental modification was encountered, although the solubility of the partially crystalline suberin depended strongly on the actual ink medium. Suberin extracted from cork wastes by a simple procedure (Cordeiro, 1998a) is a cheap material which would compete favourably with additives commonly used to modify specific properties of printing inks. Work is therefore in progress to widen the nature of the substrates and to extend this study towards the more relevant context related to printing performance, in order to assess the interest of using suberin as a viable additive to improve the quality of printing inks. 


\section{Acknowledgements}

The authors wish to thank the French-Portuguese Scientific Cooperation Programme and JNICT Portugal for financial support and the companies which kindly provided the cork and ink samples.

\section{References}

Blayo, A., Noel, N., LeNest, J.F., Gandini, A., 1993. A comparative rheological study of waterless and conventional offset inks. Printing Inks 4, 164-171.

Blayo, A., Gandini, A., 1996. Printing inks. In: The Polymeric Materials Encyclopedia, vol. 11. CRC Press, pp. 72397250.

Cordeiro, N., Neto, C.P., Gandini, A., Belgacem, M.N., 1995. Characterization of the cork surface by inverse gas chromatography. J. Coll. Interface Sci. 174, 246-249.

Cordeiro, N., Aurenty, P., Belgacem, M.N., Gandini, A., Pascoal Neto, C., 1997a. Surface properties of suberin. J. Coll. Interface Sci. 187, 498-508.

Cordeiro, N., Belgacem, M.N., Gandini, A., Pascoal Neto, C., 1997b. Urethanes and polyurethanes from suberin: 1. Kinetic study. Ind. Crops Prod. 6, 163-167.

Cordeiro, N., 1998a. Fraccionamento e caracterização da cortiça e dos seus constituintes. Estudo de possibilidades de valorização da suberina. Doctoral thesis, University of Aveiro.

Cordeiro, N., Belgacem, M.N., Gandini, A., Pascoal Neto, C., 1998b. Cork suberin as a new source of chemical. 1. Extraction and chemical characterization. Int. J. Biol. Macromol. 22, 71-82.

Cordeiro, N., Belgacem, M.N., Gandini, A., Pascoal Neto, C., 1998c. Cork suberin as a new source of chemicals. 2. Crystallinity, thermal and rheological properties. Biores. Technol. 63 (2), 153-158.

Cordeiro, N., Belgacem, M.N., Gandini, A., Pascoal Neto, C., 1999. Urethanes and polyurethanes from suberin: 2. Syn- thesis and characterization. Ind. Crops Prod. 10, 1-10.

Gil, A.M., Lopes, M., Rocha, J., Pascoal Neto, C., 1997. A

${ }^{13} \mathrm{C}$ nuclear magnetic resonance spectroscopy study of cork cell wall structure: the effect of suberin removal. Int. J. Biol. Macromol. 20, 293-305.

Godinho, M.H., Gil, L., Martins, A.F., 1998. Mechanical properties of new composite solid films of hydroxypropylcellulose and cork powder, Materials Congress'98, Cirencester, UK, 6-8 April.

Holloway, P.J., 1972. The composition of suberin from the corks of Quercus suber L. and Betula pendula R. Chem. Phys. Lipids 9, 158-170.

Holloway, P.J., 1983. Some variations in the composition of suberin from the cork layers of higher plants. Phytochemistry $22(2), 495-502$.

Kolattukudy, P.E., 1977. Lipid polymers and associated phenols, their chemistry, biosynthesis, and role in pathogenesis. In: Loewus, F.A., Runeckles, V.C. (Eds.), The Structure, Biosynthesis and Degradation of Wood. Plenum Press, New York, p. 185.

Lanet, V., Gandini, A., 1999. The use of vegetable oils in waterless inks: implications regarding the rheological, physico-chemical and printability characteristics. J. Prepress Print. Technol. 3, 12-20.

Lopes, M., Pascoal Neto, C., Evtuguin, D., Silvestre, A., Cordeiro, N., Gandini, A., 1998. Products of permanganate oxidation of cork, desuberized cork, suberin and lignin. Holzforschung 52, 146-148.

Marques, A.V., Pereira, H., 1987. On the determination of suberin and other structural components in cork from Quercus suber L. Anais ISA 42, 321-335.

Pascoal Neto, C., Rocha, S., Gil, A., Cordeiro, N., Esculcas, A., Pedrosa de Jesus, J.P., Rocha, S., Delgadillo, I., Ferrer Correia, A.J., 1995. Solid-state nuclear magnetic resonance and Fourrier transform infrared studies of thermal decomposition of cork. Solid State NMR 4, 143-151.

Pascoal Neto, C., Cordeiro, N., Seca, A., Domingues, F., Gandini, A., Robert, D., 1996. Isolation and characterization of a lignin-like polymer of cork of Quercus suber L. Holzforschung 50, 563-568.

Pereira, H., 1988. Chemical composition and variability of cork from Quercus suber L. Wood Sci. Technol. 22, 211218 . 